\title{
Knowledge about cervical cancer and awareness about human papillomavirus vaccination among medical students in Jordan
}

\author{
Mervat M Alsous ${ }^{\text {Corresp., } 1}$, Ahlam Ali ${ }^{2}$, Sayer Al-Azzam ${ }^{3}$, Reema Karasneh ${ }^{4}$, Haneen Amawi ${ }^{1}$ \\ ${ }^{1}$ Department of Clinical Pharmacy and Pharmacy Practice, Faculty of Pharmacy, Yarmouk University, Irbid, Irbid governorate, Jordan \\ Medical Biology Centre, School of Medicine, Dentistry and Biomedical Sciences, Queen's University Belfast, Belfast, United Kingdom \\ 3 \\ 4 \\ Department of Basic Medical Sciences, Faculty of Medicine, Yarmouk University, Irbid, Irbid governorate, Jordan \\ Corresponding Author: Mervat M Alsous \\ Email address: mervat.alsous@yu.edu.jo
}

Objectives To assess the knowledge about cervical cancer and HPV infection and the awareness towards and perceived barriers of HPV vaccination amid medical students in Jordan.

Methods The present study is a cross-sectional survey that was conducted for a period of three months in the College of Medicine at six different universities in Jordan. Third-year to sixth-year students from these medical colleges in Jordan were invited to participate in the study.

Results There were 504 students that took part in the study with $42.3 \%$ being males and $57.7 \%$ females. The mean knowledge score of students in our survey was $21.4 \pm 4.4$ out of 34 , which was categorized as a moderate level of knowledge regarding cervical cancer and HPV. Only $40.5 \%$ knew about the availability of the HPV vaccine in Jordan, and $65.9 \%$ accepted the idea that it is necessary to introduce the HPV vaccine for school girls in Jordan.

Conclusions This study highlights that there is inadequate knowledge about cervical cancer and its screening among medical students in Jordan. Despite the limited awareness about the HPV vaccine among the study's participants, there is a favorable opinion towards the introduction of the vaccine for school girls in Jordan. The data provide a benchmark on the level of knowledge about cervical cancer and awareness about HPV, which can be used to formulate an effective awareness program. 
1 Knowledge about Cervical Cancer and Awareness about Human Papillomavirus

2

\section{Vaccination among Medical Students in Jordan}

\section{Mervat Alsous ${ }^{1 *}$, Ahlam Ali ${ }^{2}$, Sayer Al-Azzam ${ }^{3}$, Reema Karasneh ${ }^{4}$, Haneen Amawi ${ }^{1}$}

${ }^{1}$ Department of Clinical Pharmacy and Pharmacy Practice, Faculty of Pharmacy, Yarmouk University, Irbid, Jordan

${ }^{2}$ Medical Biology Centre, School of Medicine, Dentistry and Biomedical Sciences, Queen's University Belfast, Belfast, United Kingdom

${ }^{3}$ Department of Clinical Pharmacy, Faculty of Pharmacy, Jordan University of Science and Technology, Irbid, Jordan

${ }^{4}$ Department of Basic Medical Sciences, Faculty of Medicine, Yarmouk University, Irbid, Jordan

*Corresponding Author: Dr. Mervat Alsous, PhD.

Department of Clinical Pharmacy and Pharmacy Practice, Faculty of Pharmacy, Yarmouk University, Irbid, Jordan

Email: mervat.alsous@yu.edu.jo 
29

30

31

32

33

34

\section{Abstract \\ Objectives}

To assess the knowledge about cervical cancer and HPV infection and the awareness towards and perceived barriers of HPV vaccination amid medical students in Jordan.

\section{Methods}

The present study is a cross-sectional survey that was conducted for a period of three months in the College of Medicine at six different universities in Jordan. Third-year to sixth-year students from these medical colleges in Jordan were invited to participate in the study.

\section{Results}

There were 504 students that took part in the study with $42.3 \%$ being males and $57.7 \%$ females. The mean knowledge score of students in our survey was $21.4 \pm 4.4$ out of 34 , which was categorized as a moderate level of knowledge regarding cervical cancer and HPV. Only 40.5\% knew about the availability of the HPV vaccine in Jordan, and $65.9 \%$ accepted the idea that it is necessary to introduce the HPV vaccine for school girls in Jordan.

\section{Conclusions}

This study highlights that there is inadequate knowledge about cervical cancer and its screening among medical students in Jordan. Despite the limited awareness about the HPV vaccine among the study's participants, there is a favorable opinion towards the introduction of the vaccine for school girls in Jordan. The data provide a benchmark on the level of knowledge about cervical cancer and awareness about HPV, which can be used to formulate an effective awareness program.

\section{Keywords: Cervical cancer, Jordan, knowledge, medical students, Human Papillomavirus,} vaccine 
58 Cervical cancer (CC) is the most common gynecologic malignancy worldwide and the fourth most

59

60

61

62

63

64

65

66

67

68

69

70

71

72

73

74

75

76

77

78

79

80

81

82

83

84 1. Introduction common cancer in women. Most cases of cervical cancer are attributed to Human Papillomavirus (HPV). Assessment of the knowledge about cervical cancer and HPV vaccination is needed.

\section{What does this paper add?}

The awareness of physicians and medical students will greatly impact the success of cervical cancer prevention. This is the first study in Jordan that assesses the knowledge about cervical cancer and awareness about the HPV vaccine among medical students. The current study highlights the need for a proper educational campaign about cervical cancer and the HPV vaccine. 

the Middle East, CC affects 19,500 women per year, leading to 9,930 deaths annually. By 2035, these numbers are expected to double in this region unless effective public health interventions are introduced [1].

CC, caused by human papillomavirus (HPV), is the major cause of years of life lost to cancer in the developing world. Since it affects women in their most productive years, CC has a disturbing effect on the well-being of families [2]. In Jordan, current estimates indicate that 104 women are diagnosed with cervical cancer every year and 61 die from the disease. Data on the HPV burden in the general population of Jordan is not yet available [3]. However, in Western Asia, where Jordan is located, $72.4 \%$ of invasive cervical cancers are attributed to certain types of HPV [1]. Therefore, conducting comprehensive evaluations of HPV prevalence and examining the knowledge, attitudes, and practices toward HPV vaccination will provide a clear description of the situation in the region. Introducing a successful HPV vaccination program will directly reduce morbidity and mortality from HPV types, improve women health, increase healthcare cost savings, and extend positive externalities on women's immediate communities.

Amongst all known risk factors, persistent infection from high-risk HPV plays a considerable role in the pathogenesis of CC. The available screening tests for cervical cancer include conventional and liquid-based cytologic tests (i.e., Pap tests) while the most common test to detect HPV is to use a polymerase chain reaction (PCR) assay [4]. Almost all cases of CC are attributed to HPV, with subtypes 16 and 18 accounting for more than half of the CC cases 
107

108

109

110

111

112

113

114

115

116

117

118

119

120

121

122

123

124

125

126

127

128

additional HPV types $(31,33,35,39,45,51,52,56,58$, and 59) are associated with cervical cancer as they have adequate evidence of carcinogenicity in humans. On the other hand, other HPV types, including types 6 and 11, can cause genital warts, benign or low-grade cervical cell changes, and recurrent respiratory papillomatosis [4].

Successful achievements in basic and clinical research have expanded the possibilities of CC prevention by introducing HPV testing as part of the screening technology and, most importantly, by the production of efficacious prophylactic HPV vaccines [7]. It is established that well-organized cervical screening programs or widespread good quality cytology can reduce CC incidence and mortality. Diagnostic screening programs for HPV lesions are generally available in the developed countries. However, all Middle East countries including Jordan do not have a national CC screening program due to the lack of public health policy, professional and general education, clinical settings, financial resources, and media awareness. Noteworthy, most female cancer awareness campaigns in the Middle East are mainly focused on breast cancer [10]. The first vaccine against HPV for the primary prevention of CC was licensed in 2006 by the Food and Drug Administration (FDA) of the United States of America (USA). Currently, two prophylactic vaccines against HPV are registered: quadrivalent Gardasil (Merck, USA) and bivalent Cervarix (GlaxoSmithKline, Belgium). Both vaccines have good profiles for efficacy in preventing HPV infection and are well tolerated. Published studies have recognized a high efficacy of over $92 \%$ against precancerous lesions among women [11]. However, the uptake of these vaccines has been slow in the extended Middle East and North Africa regions due to several factors such as financial limits, weak infrastructure for adolescent vaccine delivery, lack of reliable data on the burden of HPV disease, and competition with high priority vaccines. Other barriers 
129 include religious and cultural sensitivities as the vaccines are given to prevent a sexually

130 transmitted disease in young girls.

131 Several studies, mostly from developed countries, have demonstrated that the

132 knowledge about HPV infection and the acceptability of HPV vaccines amongst health care

133 professionals and the general public vary from low to high [12-15]. Recommendation of HPV

134 immunization by physicians has been recognized as one the most significant factors in the

135 individual's willingness to receive the vaccine. Updated knowledge about the HPV vaccine and

136 the elimination of any barriers to prescriptions among physicians are the main determinant

137 factors [16-17].

Physicians can play an imperative role in circulating knowledge about CC and the available preventive vaccines. Therefore, the awareness of physicians and medical students will greatly impact the success of CC prevention. The awareness programs should focus on family physicians and gynecologists depending on the known immunizer in each country. Targeted community education that responds to concerns about the HPV vaccine has proven to be effective [18]. It is therefore important to enhance promotion, communication, and social mobilization strategies to increase awareness among decision makers and demand among the population. The strategy should include several companion organizations in the communities such as non-governmental organizations, women's groups, religious leaders, and professional organizations. and awareness towards and perceived barriers of HPV vaccination among medical students in 
151 to modify population behavior. This is the first time in Jordan that the assessment of their

152 knowledge about CC and HPV is being done.

153 2. Methods

\section{$154 \quad 2.1$ Study Design and Purpose}

The present study is a cross sectional survey that was designed to investigate the

knowledge about CC and awareness about the HPV vaccine among medical students in Jordan.

\subsection{Study Participants and Ethical Considerations}

The protocol of the study was approved by the Scientific Research Committee at Yarmouk

University. The study was conducted after obtaining ethical approval from the Institutional

Review Board (IRB) of Jordan University of Science and Technology (JUST) and King Abdulla

University Hospital (KAUH), Irbid, Jordan (13/128/2019).

The questionnaire was distributed utilizing an electronic format, through Google Forms.

The link to the survey was shared with medical students in six universities in Jordan. The questionnaire was prefaced by a page explaining the nature and objectives of the study and the voluntary nature of participation with a consent statement if they would like to take part in the study. Participants who completed the questionnaire gave electronic informed consent by declaring their acceptance to fill out the questionnaire. The questionnaire was terminated automatically if participants declined to take part. This procedure was approved by the IRB committee. 
The participants were assured that the outcomes of the research would not be used for

171

routine appraisal of the participants. The individuals were requested to complete the questionnaire without textbooks or consulting materials.

The study was conducted for a period of three months in the College of Medicine at six different universities in Jordan. Third-year to sixth-year medical students from these medical colleges in Jordan were invited to participate in the study.

\subsection{Study Instruments}

The study questionnaire was developed by authors after an extensive review of literature. A pre-validated questionnaire, consisting of items modified from questionnaires in other studies $[17,19]$ was used. The questionnaire was reviewed by the authors and then subjected to pilot testing by 30 participants to ensure the clarity of the questions, which resulted in several minor amendments.

The final version of the questionnaire consisted of three parts. The first one was about the demographic information of participants which included age, gender, year of study, and average monthly income. The second part assessed the knowledge of participants about CC and HPV. Finally, the third part assessed the participants' awareness and acceptance of HPV vaccination.

The knowledge of the students about CC was evaluated using 14 multiple choice questions with 34 statements related to disease etiology, risk factors, clinical features, and screening recommendations according to the World Health Organization (WHO). Each answer was scored as incorrect or correct. The respondent was given a zero point for each wrong answer and one point for each correct answer. 
19434 , respectively.

Regarding respondents' awareness about HPV vaccination, this part consisted of seven questions. Each question was scored out of two points. A poor awareness level was allocated to the medical students with a maximum $39 \%$ of awareness mean score (0-5 points), an average awareness to those with at a $40-69 \%$ of awareness mean (6-9 points), and a good awareness level to people with over $70 \%$ of awareness mean (10-14 points).

The last three questions in the questionnaire assessed the acceptance of HPV vaccination among medical students in Jordan, the perceived barriers of HPV vaccination, and their source of information about it.

\subsection{Statistical Analysis}

Data was analyzed using SPSS software version 24. Descriptive data was expressed as frequencies and percentages. Chi square was used to analyze significant differences between categorical variables. Student's t-tests were used to compare the means between two groups. Analysis of Variance (ANOVA) was used to compare the means between three or more groups. Analysis of Variance (ANOVA) was used to compare the means between three or more groups. alpha coefficient $(\alpha)$, values $\geq 0.70$ were considered adequate. All $p$-values were two sided and any $p$-value of less than 0.05 was considered statistically significant. 


\subsection{Sample Size Calculation}

214

Around 9,218 students are currently enrolled to study medicine at Jordanian universities

215

[20]. The sample size was calculated utilizing the online Raosoft software sample size calculator.

The minimum required sample size assuming a 95\% confidence level, 50\% recruitment rate, 5\%

margin of error, and a maximal sample size of 6,000 students would be 362 participants.

\section{Results}

\subsection{Demographic Characteristics}

The number of total responses was 508 , with 4 students disagreeing to take part in the

study and 504 of the students completing the questionnaire. Recruited students were from all six medical colleges in Jordan including Yarmouk University (33.3\%), Jordan University of Science

University (6.3\%), and Albalqa University (5.8\%). About $42.3 \%$ were males and the mean age was

$22.3 \pm 1.6$ years. Table 1 shows participants' demographic characteristics. The questionnaire was deemed reliable based on the result of Cronbach alpha coefficient $(0.759)$ and its $95 \% \mathrm{Cl}(0.728$ 0.788).

\subsection{Knowledge Assessment about CC} diagnosis, risk factors, symptoms, and relation to HPV. In regards to knowledge about CC, the mean knowledge score for students was $21.4 \pm 4.4$. Table 2 shows the proportion of students who correctly answered questions related to CC and HPV. Most participants knew that CC is 
233 caused by an infection ( $n=413,81.9 \%)$ and that HPV is responsible for a wide array of diseases

234 including CC ( $n=455,90.3 \%)$.

235 Concerning its epidemiology, $60.7 \%$ of students answered correctly that CC is a leading

236 cause of gynecological cancer.

Student knowledge about the clinical features of CC and percentages of correct answers were $35.5 \%$ for no symptoms and $80.6 \%$ for bleeding of the vagina. The percentages of students who were aware that fever, itching, and swelling of the cervix were not among the clinical features of the disease were $87.5 \%, 70.0 \%$, and $54.85 \%$ respectively. The mean percentage knowledge score of this part was $59.7 \% \pm 16.5 \%$. correctly that women aged $45-60$ years should screen according to WHO once every 5 years. On the other hand, $76.6 \%$ were aware that there is a vaccine that protects from CC. The mean percentage knowledge score of this part was $55.2 \% \pm 25.9 \%$. students were aware that HPV subtypes 6 and 11 are commonly associated with genital warts (65.1\%) and HPV subtypes 16 and 18 are commonly associated with CC (70.4\%). The mean percentage knowledge score of this domain was $67.9 \% \pm 21.5 \%$. and analysis of variance and there was a significant difference between the mean knowledge score for male students $20.6 \pm 4.7$ compared to female students $22.0 \pm 4.0(p$-value $=0.001)$. The 
254 knowledge score was significantly associated with the year of study with the highest mean score

255 among students in the sixth year with $23.6 \pm 3.5(p$-value $<0.001)$ and the least mean score

256 among third-year students $18.4 \pm 4.2$. There was no significant association between family

257 income, place of living, or nationality and knowledge score ( $p$-value $>0.05)$.

\section{3.3 Awareness about HPV Vaccine and Acceptance}

Regarding student's awareness about the HPV vaccine, only $40.5 \%$ knew about the availability of the HPV vaccine in Jordan, $71.4 \%$ were aware that the HPV vaccine should be given at an age between 11 and 29, and about half (54.0\%) knew that it could be given to boys also.

There were $21.0 \%$ that were familiar that girls or women do not need to be screened for HPV before getting vaccinated and that CC protection provided by the HPV vaccine is $70 \%$. Less than one third of the students (30.8\%) were aware that the HPV vaccine cannot be given to a woman already having HPV infection while $19.0 \%$ of students knew that three doses are required for protection in women. The mean awareness score of students about the HPV vaccine was $5.7 \pm$ 2.8 with a range $0-13$ which is classified as average awareness (Table 3 ). level of study as there was a significant difference between the mean awareness score for students in the sixth year with $6.3 \pm 2.8$ (p-value $<0.001)$. On the other hand, the awareness score was not associated with all other demographic data ( $p$-value $>0.05$ ) as shown in Table 4. the HPV vaccine for schoolgirls in Jordan. The association of demographic data with the 
276 acceptance of introducing the vaccine was not associated with all other demographic data nor

277 with the knowledge score or awareness score ( $p$-value $>0.05)$.

Among the obstacles that prevent the receipt of the vaccine or advice about taking HPV vaccination were high cost (53.8\%) and inadequate information about the vaccine (62.5\%) as shown in Figure 1.

Figure 2 presents the sources of information about HPV vaccination which were reported by students as medical school teaching being the main source of information $(87.7 \%)$ followed by internet sources (33.3\%) and books (23.2\%).

\section{Discussion}

In the current study, general CC and HPV knowledge was moderate which was similar to

the result of a study done with medical, dental, and nursing students in South India [21]. Most of participants in the present study were aware that CC is caused by an infection and that the HPV infection can lead to CC. These results show adequate knowledge about CC epidemiology and are similar to other studies conducted with health care professionals $[15,22]$.

In our study, most medical students were able to recognize that infection and risky sexual practices are common risk factors for CC; these results were similar to other studies [23-25].

However, some students had incorrect information that old age and nulliparity were among the risk factors of CC. In the current study, a high percentage of participants were unaware that lower pelvic pain and anemia are common clinical features of $\mathrm{CC}$, and some of them wrongly thought that fever, itching, and swelling of the cervix were symptoms of CC. This highlights the need to 
296 increase the consciousness about CC among physicians who act as the main source of health

297 information to their patients.

Less than half of students correctly reported PCR as a test used for the detection of HPV infection and knew the appropriate frequency of CC screening in women (i.e., women aged 2544 years should be screened every three years and women aged 45-60 years should be screened every 5 years). This showed an inadequacy of knowledge which is important as a preventive measure for CC. In addition, the knowledge score was significantly associated with gender and year of study and this was consistent with other studies where the score was higher among female students [26-27] and higher level of study [28]. studies have been conducted worldwide recently on the knowledge, attitude, beliefs, and awareness about the HPV vaccine $[15,22,30-32]$. In the current study, only $40.5 \%$ of medical students were aware of the availability of the HPV vaccine in Jordan which protects from CC and about $20.0 \%$ were aware that there is no need to screen girls before getting vaccinated. Also, $70 \%$ were aware that CC protection is provided by the HPV vaccine. This could be due to the lack of awareness and guidance campaigns in Jordan to shed light on the importance of this vaccine, and it has not been introduced officially in the national vaccination program in Jordan. In addition, topics about cervical cancer and the HPV vaccine are not sufficiently addressed in the curricula of medical schools. woman already having the HPV infection, and $19 \%$ of students knew that the appropriate number

317 of doses of the HPV vaccine is three with an overall awareness score of $5.7 \pm 2.8$. This indicates 
318 an inadequate awareness about the HPV vaccine which was similar to a result from a study of

319 university students in India [33].

320 In the current study, about two thirds of students (65.9\%) thought that it is important to

321 introduce the vaccine in school girls in Jordan which indicates a favorable acceptance of using

322 the vaccine in Jordan. Hoque et al. (2016) indicated that most of the physicians in their study 323 reported that they intended to prescribe the HPV vaccine to patients as they expected an 324 important advantage from HPV vaccination [34].

In the present study, more than half of the students (62.5\%) reported inadequate

information about CC and the HPV vaccine as an obstacle preventing the receipt of the vaccine or advice about taking HPV vaccination. Our results were similar to a study on medical students in India [17]. Therefore, it is recommended that physicians should receive information about HPV from educational campaigns to improve their communication practices for recommending HPV vaccination [35].

\section{Strength and Limitations of the Study}

The high response rate and the inclusion of all medical colleges in Jordan enhance the generalizability of our results. However, this is a cross sectional study and therefore causal relationships between variables cannot be established. We could also not detect the response rate as the questionnaire was distributed electronically. In addition, a systematic sampling method must be used to identify respondents from each level, but a convenient sampling method 
338 considered a starting point for future studies on this sensitive topic exploring the attitudes and

339 barriers to vaccination among women in Jordan.

\section{Conclusion}

This study highlights insufficient knowledge about CC and its screening among medical students in Jordan. Despite the limited awareness about the HPV vaccine among the study's participants, there is a favorable opinion towards the introduction of the vaccine in school girls in Jordan. More emphasis should be placed on the medical curriculum taught in undergraduate education. Suitable educational campaigns should be stratified at hospitals along with workshops and seminars which highlight the importance of CC screening in women and increase the awareness about HPV among physicians. Medical students who are the future health care providers can educate their patients, address their sensitive cultural concerns, and later increase the health seeking behavior in women in Jordan especially if they are properly aware of CC and hence its burden reduced.

\section{Acknowledgements}

Thanks to all the members of the medical students who participated in this study.

\section{Funding}

No funding was obtained for this manuscript.

\section{Ethics Approval and Consent to Participate}


357 Science and Technology (JUST) and King Abdulla University Hospital (KAUH), Irbid, Jordan

358 (13/128/2019). All study participants provided informed consent to participate in the study.

359 Consent for Publication

360

Not applicable.

\section{Availability of Data and Materials}

Raw data of the study is available as supplementary data.

363

364

365

366

367

368

369

370

371

372

373

374

375

376

377

378

379

\section{Competing Interests}

The authors declare that they have no competing interests.

65

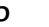


380

381

382

383

384

385

386

387

388

389

390

391

392

393

394

395

396

397

398

399

400

401

402

403

404

405

406

407

408

409

410

411

412

413

\section{References}

1. World Health Organization, (2020) Cervical cancer. Available from: (https://who.int/cancer/prevention/diagnosis-screening/cervical-cancer/en/).

2. World Health Organization (2019) Human papillomavirus (HPV) and cervical cancer. https://www.who.int/news-room/fact-sheets/detail/human-papillomavirus-(hpv)-and-cervical-cancer

3. Jordan Human Papillomavirus and Related Cancers, Fact Sheet (2018). Available from: (https://hpvcentre.net/statistics/reports/JOR_FS.pdf).

4. Gargano, J., Meites, E., Watson, M., Unger, E., \& Markowitz, L. (2017). Manual for the Surveillance of Vaccine-Preventable Diseases.

5. Schiffman, M., Castle, P. E. (2003) Human papillomavirus: epidemiology and public health. Arch Pathol Lab Med, 127: 930-4. 4.

6. Trottier, H., Franco, E. L. (2005) The epidemiology of genital human papillomavirus infection. Vaccine, 24: S1-15. 5.

7. Franco, E., Harper, D. M. (2005) Vaccination against human papillomavirus infection: a new paradigm in cervical cancer control. Vaccine, 23: 2388-94. 6.

8. Munoz, N., Bosch, F. X., de Sanjose, S., Herrero, R., Castellsague, X., Shah, K.V., Snijders, P. J. F., \& Meijer, C. J. M.. (2003) Epidemiologic classification of human papillomavirus types associated with cervical cancer. $N$ Eng J Med, 348: 518-27.

9. Lee, A., Chan, P. K. S. (2012) Interim result for school based cervical cancer education and prevention programme. 50th Anniversary Multidisciplinary Conference, The Hong Kong Paediatric Society, Hong Kong, 17-19 Aug 2012.

10. Jumaan, A.O., Ghanem, S., Taher, J., Braikat, M., Al Awaidy, S. and Dbaibo, G.S., (2013) Prospects and challenges in the introduction of human papillomavirus vaccines in the extended Middle East and North Africa region. Vaccine, 31, pp. G58-G64.

11. World Health Organization (2009). WHO position on HPV vaccines Vaccine;27(52):7236-7.

12. Chawla, P. C., Chawla, A., \& Chaudhary, S. (2016) Knowledge, attitude \& practice on human papillomavirus vaccination: A cross-sectional study among healthcare providers. The Indian journal of medical research, 144(5), 741.

13. Warner, E. L., Ding, Q., Pappas, L., Bodson, J., Fowler, B., Mooney, R., \& Kirchhoff, A. C., Kepka, D. (2017) Health care providers' knowledge of HPV vaccination, barriers, and strategies in a state with low HPV vaccine receipt: mixed-methods study. JMIR cancer, 3(2), e12.

14. Pereira, J. E. G., Gomes, J. M., Costa, A. D. S., Figueiredo, F. W. D. S., Adami, F., Santos, E. F. D. S., Sorpreso, I. C. E., \& de Abreu, L. C. (2019) Knowledge and acceptability of the human papillomavirus vaccine among health professionals in Acre state, western Amazon. Clinics, 74. 
414

415

416

417

418

419

420

421

422

423

424

425

426

427

428

429

430

431

432

433

434

435

436

437

438

439

440

441

442

443

444

445

446

447

15. Sherman, S. M., Cohen, C. R., Denison, H. J., Bromhead, C., \& Patel, H. (2020) A survey of knowledge, attitudes and awareness of the human papillomavirus among healthcare professionals across the UK. European Journal of Public Health, 30(1), 10-16.

16. Riedesel, J. M., Rosenthal, S. L., Zimet, G. D., Bernstein, D. I., Huang, B., Lan, D., \& Kahn, J. A. (2005) Attitudes about human papillomavirus vaccine among family physicians. Journal of pediatric and adolescent gynecology, 18(6), 391-398.

17. Pandey, D., Vanya, V., Bhagat, S., Vs, B., \& Shetty, J. (2012) Awareness and attitude towards human papillomavirus (HPV) vaccine among medical students in a premier medical school in India. PloS one, 7(7).

18. Leung, S. O. A., Akinwunmi, B., Elias, K. M. and Feldman, S. (2019) Educating healthcare providers to increase human papillomavirus (HPV) vaccination rates: A Qualitative Systematic Review. Vaccine, pp. 100037.

19. Aljuwaihel, A., Al-Jarallah, A., Al-Busairi, H., \& El-Shazly, M. K. (2013) Awareness of HPV and Cervical Cancer Vaccine among PHC Physicians in Kuwait. Greener Journal of Medical Sciences, 3(4), 152-159.

20. Goussous, S. (2016). 13,000 Jordanian studying medicine abroad. Jordan Times. https://www.jordantimes.com/news/local/13000-jordanians-studying-medicine-abroad\%E2\%80\%99.

21. Shetty, S., Prabhu, S., Shetty, V., \& Shetty, A. K. (2019). Knowledge, attitudes and factors associated with acceptability of human papillomavirus vaccination among undergraduate medical, dental and nursing students in South India. Human vaccines \& immunotherapeutics, 15(7-8), 1656-1665.

22. Almazrou, S., Saddik, B., \& Jradi, H. (2019) Knowledge, attitudes, and practices of Saudi physicians regarding cervical cancer and the human papilloma virus vaccine. Journal of Infection and Public Health, 13(4), 584590.

23. Jolly, P. E., Mthethwa-Hleta, S., Padilla, L. A., Pettis, J., Winston, S., Akinyemiju, T. F., Turner, H. J., Ejiawoko, A., Brooks, R., Preko, L., \& Preko, P. O. (2017) Screening, prevalence, and risk factors for cervical lesions among HIV positive and HIV negative women in Swaziland. BMC public health, 17(1), 218.

24. Melan, K., Janky, E., Macni, J., Ulric-Gervaise, S., Dorival, M. J., Veronique-Baudin, J., \& Joachim, C. (2017) Epidemiology and survival of cervical cancer in the French West-Indies: data from the Martinique Cancer Registry (2002-2011). Global health action, 10(1), 1337341.

25. Goldsmith, M. R., Bankhead, C. R., Kehoe, S. T., Marsh, G., \& Austoker, J. (2007) Information and cervical screening: a qualitative study of women's awareness, understanding and information needs about HPV. Journal of Medical Screening, 14(1), 29-33.

26. Hussain, S., Nasare, V., Kumari, M., Sharma, S., Khan, M. A., Das, B. C., \& Bharadwaj, M. (2014) Perception of human papillomavirus infection, cervical cancer and HPV vaccination in North Indian population. PLOS One, 9(11), e112861.

27. Ngwenya, D., \& Huang, S. L. (2018) Knowledge, attitude and practice on cervical cancer and screening: a survey of men and women in Swaziland. Journal of Public Health, 40(3), e343-e350.

Peer) reviewing PDF | (2021:03:58829:1:1:NEW 5 May 2021) 
28. Tesfaye, Z. T., Bhagavathula, A. S., Gebreyohannes, E. A., \& Tegegn, H. G. (2019) Knowledge and awareness of cervical cancer and human papillomavirus among female students in an Ethiopian University: A crosssectional study. International journal of preventive medicine, 10.

29. Santhanes, D., Yong, C. P., Yap, Y. Y., San Saw, P., Chaiyakunapruk, N., \& Khan, T. M. (2018) Factors influencing intention to obtain the HPV vaccine in South East Asian and Western Pacific regions: A systematic review and meta-analysis. Scientific reports, 8(1), 1-11.

30. Jradi, H. \& Bawazir, A. (2019) Knowledge, attitudes, and practices among Saudi women regarding cervical cancer, human papillomavirus (HPV) and corresponding vaccine. Vaccine, 37(3), 530-537.

31. Maness, S. B., Reitzel, L. R., Watkins, K. L., \& McNeill, L. H. (2016) HPV awareness, knowledge and vaccination attitudes among church-going African-American women. American journal of health behavior, 40(6), 771-778.

32. Kasymova, S., Harrison, S. E. \& Pascal, C. (2019) Knowledge and awareness of human papillomavirus among college students in South Carolina. Infectious Diseases: Research and Treatment, 12, 1178633718825077.

33. Gollu, A. N., \& Gore, C. A. (2021). Knowledge, Awareness and Attitude of Medical Students Regarding HPV Infection and HPV Vaccination. Asian Pacific Journal of Cancer Care, 6(1), 41-46.

34. Hoque, M. E. (2016) Factors influencing the recommendation of the Human Papillomavirus vaccine by South African doctors working in a tertiary hospital. African health sciences, 16(2), 567-575.

35. Hswen, Y., Gilkey, M. B., Rimer, B. K. \& Brewer, N. T. (2017) Improving physician recommendations for HPV vaccination: the role of professional organizations. Sexually transmitted diseases, 44(1), 42. 
482 Table 3: Participant's awareness and acceptance of HPV vaccination $(n=504)$

\begin{tabular}{|c|c|c|}
\hline Question & $\begin{array}{l}\text { Correct answer } \\
\text { N (\%) }\end{array}$ & $\begin{array}{l}\text { Wrong answer } \\
\text { N (\%) }\end{array}$ \\
\hline 1.Is the HPV vaccine available in Jordan ${ }^{1}$ & $204(40.5)$ & $300(59.5)$ \\
\hline --Yes (2 points) & $204(40.5)$ & \\
\hline- No & $64(12.7)$ & \\
\hline -Don't know & $236(46.8)$ & \\
\hline 2.Which age group HPV vaccine should be given? & $443(87.9)^{*}$ & $51(12.1)$ \\
\hline$-(0-10)$ Years & $48(9.5)$ & \\
\hline$-(11-29)$ Years (2 points) & $360(71.4)$ & \\
\hline$-(30-50)$ Years (1 point) & $83(16.5)$ & \\
\hline -(51) years and above & $13(2.6)$ & \\
\hline 3.Can HP vaccine be given to boys? 1 & $272(54.0)$ & $132(46.0)$ \\
\hline -Yes (2 points) & $272(54.0)$ & \\
\hline- No & $50(9.9)$ & \\
\hline -Don't know & $182(36.1)$ & \\
\hline $\begin{array}{l}\text { 4.Do girls/women need to be screened for HPV before } \\
\text { getting vaccinated?2 }\end{array}$ & $109(21.6)$ & $395(78.4)$ \\
\hline$-Y e s$ & $237(47.0)$ & \\
\hline -No (2 points) & $109(21.6)$ & \\
\hline -Don't know & $158(31.4)$ & \\
\hline $\begin{array}{l}\text { 5.Can HP vaccine be given to a woman already having } \\
\text { HPV infection?2 }\end{array}$ & $155(30.8)$ & $349(69.2)$ \\
\hline- Yes & $141(28.0)$ & \\
\hline -No (2 points) & $155(30.8)$ & \\
\hline -Don't know & $208(41.2)$ & \\
\hline $\begin{array}{l}\text { 6.How many doses of HPV vaccine are required for } \\
\text { protection in women? }\end{array}$ & $96(19.0)$ & $408(81.0)$ \\
\hline -One & $49(9.7)$ & \\
\hline -Two & 70 (13.9) & \\
\hline -Three (2 points) & $96(19.0)$ & \\
\hline -Four & $8(1.6)$ & \\
\hline -Don't Know & $281(55.8)$ & \\
\hline
\end{tabular}


$\begin{array}{lll}\text { 7.Cervical cancer protection provided by HPV vaccine } 275(54.6)^{*} & 263(45.4)\end{array}$

is:

$-100 \%$

$-90 \%$ (1 points)

21(4.2)

$-70 \%$ (2 point)

135(26.8)

$-50 \%$ (1 point)

$106(21.0)$

-Don't know

$34(6.7)$

208 (41.3)

Overall \% awareness score $=40.5 \% \pm 19.8 \%$

332 (65.9)

$172(34.1)$

4842 No

$485{ }^{*}$ Number of students who had a score of 1 or 2 points

486 
Table $\mathbf{1}$ (on next page)

Tables 
Table 1: Participant's demographic data $(n=504)$

\begin{tabular}{|c|c|}
\hline Age (Year), Mean $\pm S D$ & $22.3 \pm 1.6$ \\
\hline Age range & $20-29$ \\
\hline \multicolumn{2}{|l|}{ Gender, N (\%) } \\
\hline Male & $213(42.3)$ \\
\hline Female & $291(57.7)$ \\
\hline \multicolumn{2}{|l|}{ University, $\mathrm{N}(\%)$} \\
\hline All Public Universities in Jordan & $504(100)$ \\
\hline \multicolumn{2}{|l|}{ Level of Education, $\mathbf{N}(\%)$} \\
\hline $3^{\text {rd }}$ year & $131(26.0)$ \\
\hline $4^{\text {th }}$ year & $63(12.5)$ \\
\hline $5^{\text {th }}$ year & $113(22.4)$ \\
\hline $6^{\text {th }}$ year & $197(39.1)$ \\
\hline \multicolumn{2}{|c|}{ Know someone with cervical cancer, N (\%) } \\
\hline Yes & $22(4.4)$ \\
\hline No & $482(95.6)$ \\
\hline \multicolumn{2}{|l|}{ Nationality, N (\%) } \\
\hline Jordanian & $454(90.1)$ \\
\hline Not Jordanian & $50(9.9)$ \\
\hline \multicolumn{2}{|l|}{ Place of living, N (\%) } \\
\hline Urban & $395(78.4)$ \\
\hline Rural & $109(21.6)$ \\
\hline \multicolumn{2}{|l|}{ Family Income JD, N (\%) } \\
\hline$<500$ & $33(6.5)$ \\
\hline $501-1000$ & $128(25.4)$ \\
\hline $1001-1499$ & $111(22.0)$ \\
\hline $1500-2000$ & $94(18.7)$ \\
\hline$>2000$ & $138(27.4)$ \\
\hline
\end{tabular}

$\mathrm{N}$ : number, SD: standard deviation. 


\section{Table 2 (on next page)}

Table 2: Participant's knowledge about Cervical cancer $(n=504)$

Table 2: Participant's knowledge about Cervical cancer $(n=504)$ 
Table 2: Participant's knowledge about Cervical cancer $(n=504)$

Question

\section{Correct answer}

$\mathbf{N}(\%)$
Wrong answer

N (\%)

\section{Epidemiology of cervical cancer}

1. Is Cervical cancer the leading cause among 306 (60.7) gynecological cancer? ${ }^{1}$

2. The cause of cervical cancer

$413(81.9)$

$198(39.3)$

$91(18.1)$

Mean \% score $=71.3 \% \pm 30.8 \%$

\section{Risk factors of cervical cancer}

- Multiple sexual partner

$422(83.7)$

$82(16.3)$

-Infection with HPV

$482(95.6)$

$22(4.4)$

-Early age of first coitus

245 (48.6)

$259(51.4)$

-Smoking

301 (59.7)

$203(40.3)$

-Family History of disease

$324(64.3)$

$180(35.7)$

-Poor Hygiene

201 (39.9)

$303(60.1)$

-Old age (False)

366 (72.6)

$138(27.4)$

-Contraception

$178(35.3)$

$326(64.7)$

-Nulliparity (False)

$426(84.5)$

$78(15.5)$

Mean \% score $=64.9 \% \pm 21.0 \%$

4. Clinical features of cervical cancer

-No symptom

-Lower pelvic pain

-Bleeding per vagina

-Fever (False)*

-Discharge per vagina

-Itching (False)*

-Weight loss

-Swelling of cervix (False)*

-Anemia

-Post coital bleeding
$179(35.5)$

200 (39.7)

406 (80.6)

$441(87.5)$

318 (63.1)

$353(70.0)$

$264(52.4)$

$276(54.8)$

$202(40.1)$

$370(73.4)$
$325(64.5)$

$304(60.3)$

98 (19.4)

$63(12.5)$

186 (36.9)

$151(30.0)$

$240(47.6)$

$228(45.2)$

302 (59.9)

$134(26.6)$

Mean \% score $=59.7 \% \pm 16.5 \%$ 
Cervical cancer screening

5. Time of screening for women aged 25-44 years $180(35.7)$

6. Time of screening for women aged 45-60 years $133(26.4) \quad 371(73.6)$

7. Is there a vaccine to protect from cervical cancer? ${ }^{1} \quad 386(76.6)$

8. Does the vaccine protect against all cervical $332(65.9) \quad 172(34.1)$ cancer? ${ }^{2}$

9. Girls who have been vaccinated will need to attend for cervical cancer screening ${ }^{1}$

Mean $\%$ score $=55.2 \% \pm 25.9 \%$

\section{Knowledge about HPV}

10. Is HPV responsible for a wide range of diseases $455(90.3)$

$49(9.7)$

including cervical cancer? ${ }^{1}$

11. Transmission of HPV

$448(88.9)$

$56(11.1)$

12. The Technique available for HPV detection

- Pap smear

$376(74.6)$

$128(25.4)$

- Biopsy

$169(33.5)$

$335(66.5)$

- PCR

$218(43.3)$

$286(56.7)$

- Blood (False)*

13. HPV subtypes 6 and 11 are commonly associated with Genital warts ${ }^{1}$

14. HPV subtypes 16 and 18 are commonly associated with Cervical carcinoma ${ }^{1}$

Mean \% score $=67.9 \% \pm 21.5 \%$

\section{Overall \% Knowledge score $=63.0 \% \pm 12.9 \%$}

1 Yes

2 No

*Student get one point if the answer for this statement is false 


\section{Table 3(on next page)}

Table 3: Participant's awareness and acceptance of HPV vaccination $(n=504)$

Table 3: Participant's awareness and acceptance of HPV vaccination $(n=504)$ 
Table 3: Participant's awareness and acceptance of HPV vaccination $(n=504)$

\begin{tabular}{|c|c|c|}
\hline Question & $\begin{array}{l}\text { Correct answer } \\
\mathbf{N}(\%)\end{array}$ & $\begin{array}{l}\text { Wrong answer } \\
\text { N (\%) }\end{array}$ \\
\hline 1.Is the HPV vaccine available in Jordan ${ }^{1}$ & $204(40.5)$ & $300(59.5)$ \\
\hline -Yes (2 points) & $204(40.5)$ & \\
\hline- No & $64(12.7)$ & \\
\hline -Don't know & $236(46.8)$ & \\
\hline 2.Which age group HPV vaccine should be given? & $443(87.9)^{*}$ & $51(12.1)$ \\
\hline$-(0-10)$ Years & $48(9.5)$ & \\
\hline$-(11-29)$ Years (2 points) & $360(71.4)$ & \\
\hline$-(30-50)$ Years (1 point) & $83(16.5)$ & \\
\hline$-(51)$ years and above & $13(2.6)$ & \\
\hline 3.Can HP vaccine be given to boys? 1 & $272(54.0)$ & $132(46.0)$ \\
\hline -Yes (2 points) & $272(54.0)$ & \\
\hline$-\mathrm{No}$ & $50(9.9)$ & \\
\hline -Don't know & $182(36.1)$ & \\
\hline $\begin{array}{l}\text { 4.Do girls/women need to be screened for HPV before } \\
\text { getting vaccinated?2 }\end{array}$ & $109(21.6)$ & $395(78.4)$ \\
\hline -Yes & $237(47.0)$ & \\
\hline -No (2 points) & $109(21.6)$ & \\
\hline -Don't know & $158(31.4)$ & \\
\hline $\begin{array}{l}\text { 5.Can HP vaccine be given to a woman already having } \\
\text { HPV infection?2 }\end{array}$ & $155(30.8)$ & $349(69.2)$ \\
\hline- Yes & $141(28.0)$ & \\
\hline -No (2 points) & $155(30.8)$ & \\
\hline -Don't know & $208(41.2)$ & \\
\hline $\begin{array}{l}\text { 6.How many doses of HPV vaccine are required for } \\
\text { protection in women? }\end{array}$ & 96 (19.0) & $408(81.0)$ \\
\hline -One & $49(9.7)$ & \\
\hline$-T w o$ & 70 (13.9) & \\
\hline -Three (2 points) & $96(19.0)$ & \\
\hline
\end{tabular}




\begin{tabular}{|c|c|c|}
\hline -Four & $8(1.6)$ & \\
\hline -Don't Know & $281(55.8)$ & \\
\hline $\begin{array}{l}\text { 7.Cervical cancer protection provided by HPV vaccine } \\
\text { is: }\end{array}$ & $275(54.6)^{*}$ & $263(45.4)$ \\
\hline$-100 \%$ & $21(4.2)$ & \\
\hline$-90 \%$ (1 points) & $135(26.8)$ & \\
\hline$-70 \%$ (2 point) & $106(21.0)$ & \\
\hline$-50 \%$ (1 point) & $34(6.7)$ & \\
\hline -Don't know & $208(41.3)$ & \\
\hline Overall \% awareness score $=40.5 \% \pm 19.8 \%$ & $332(65.9)$ & $172(34.1)$ \\
\hline
\end{tabular}




\section{Table 4(on next page)}

Table 4: Knowledge and awareness about HPV vaccine scores and acceptance stratified by participants' characteristics $(n=504)$

Table 4: Knowledge and awareness about HPV vaccine scores and acceptance stratified by participants' characteristics $(n=504)$ 
Table 4: Knowledge and awareness about HPV vaccine scores and acceptance stratified by participants' characteristics ( $n=504$ )

\begin{tabular}{|c|c|c|c|c|c|c|c|c|c|c|c|}
\hline & & Knol & ledg & score & $A w$ & eness & score & & cceptance & the vaccine & \\
\hline Variable & N (\%) & Mean & SD & P-value & Mean & SD & P-value & $\begin{array}{c}\text { Yes } \\
\text { N (\%) }\end{array}$ & $\begin{array}{c}\text { No } \\
\text { N (\%) }\end{array}$ & $\begin{array}{c}\text { Don't know } \\
\text { N (\%) }\end{array}$ & P-value \\
\hline $\begin{array}{l}\text { Gender } \\
\text { Male } \\
\text { Female }\end{array}$ & $\begin{array}{l}213(42.3) \\
291(57.7)\end{array}$ & $\begin{array}{l}20.6 \\
22.0\end{array}$ & $\begin{array}{l}4.7 \\
4.0\end{array}$ & $<0.001^{*}$ & $\begin{array}{l}5.6 \\
5.7\end{array}$ & $\begin{array}{l}2.7 \\
2.8\end{array}$ & 0.626 & $\begin{array}{l}138(64.8) \\
194(66.7)\end{array}$ & $\begin{array}{l}39(18.3) \\
60(20.6)\end{array}$ & $\begin{array}{l}36(16.9) \\
37(12.7)\end{array}$ & 0.389 \\
\hline $\begin{array}{l}\text { Place of living } \\
\text { Urban } \\
\text { Rural }\end{array}$ & $\begin{array}{l}395(78.4) \\
109(21.6)\end{array}$ & $\begin{array}{l}21.5 \\
21.0\end{array}$ & $\begin{array}{l}4.2 \\
5.0\end{array}$ & 0.266 & $\begin{array}{l}5.7 \\
5.7\end{array}$ & $\begin{array}{l}2.8 \\
2.7\end{array}$ & 0.959 & $\begin{array}{c}261(66.1) \\
71(65.1)\end{array}$ & $\begin{array}{l}80(20.2) \\
19(17.4)\end{array}$ & $\begin{array}{l}54(13.7) \\
19(17.4)\end{array}$ & 0.551 \\
\hline $\begin{array}{l}\text { Nationality } \\
\text { Jordanian } \\
\text { Non-Jordanian }\end{array}$ & $\begin{array}{c}454(90.1) \\
50(9.9)\end{array}$ & $\begin{array}{l}21.5 \\
21.1\end{array}$ & $\begin{array}{l}4.4 \\
4.6\end{array}$ & 0.596 & $\begin{array}{l}5.6 \\
6.0\end{array}$ & $\begin{array}{l}2.7 \\
3.0\end{array}$ & 0.431 & $\begin{array}{c}297(65.4) \\
35(70.0)\end{array}$ & $\begin{array}{c}94(20.7) \\
5(10.0)\end{array}$ & $\begin{array}{l}63(13.9) \\
10(20.0)\end{array}$ & 0.140 \\
\hline $\begin{array}{l}\text { Know someone with } \\
\text { Cervical Cancer } \\
\text { Yes } \\
\text { No }\end{array}$ & $\begin{array}{c}22(4.4) \\
482(95.6)\end{array}$ & $\begin{array}{l}21.9 \\
21.4\end{array}$ & $\begin{array}{l}5.2 \\
4.4\end{array}$ & 0.638 & $\begin{array}{l}6.2 \\
5.6\end{array}$ & $\begin{array}{l}3.5 \\
2.7\end{array}$ & 0.373 & $\begin{array}{c}12(54.6) \\
320(66.4)\end{array}$ & $\begin{array}{c}3(13.6) \\
96(19.9)\end{array}$ & $\begin{array}{c}7(31.8) \\
66(13.7)\end{array}$ & 0.060 \\
\hline $\begin{array}{l}\text { University } \\
\text { Yarmouk University } \\
\text { University of Jordan } \\
\text { Mutah University }\end{array}$ & $\begin{array}{c}168(33.3) \\
81(16.1) \\
32(6.3)\end{array}$ & $\begin{array}{l}21.8 \\
22.4 \\
21.4\end{array}$ & $\begin{array}{l}4.3 \\
4.4 \\
4.5\end{array}$ & $<0.001^{*}$ & $\begin{array}{l}5.9 \\
5.7 \\
5.2\end{array}$ & $\begin{array}{l}2.9 \\
2.6 \\
2.6\end{array}$ & 0.272 & $\begin{array}{l}116(69.0) \\
54(66.7) \\
20(62.5)\end{array}$ & $\begin{array}{l}30(17.9) \\
15(18.5) \\
7(21.9)\end{array}$ & $\begin{array}{l}22(13.1) \\
12(14.8) \\
5(15.6)\end{array}$ & 0.644 \\
\hline
\end{tabular}




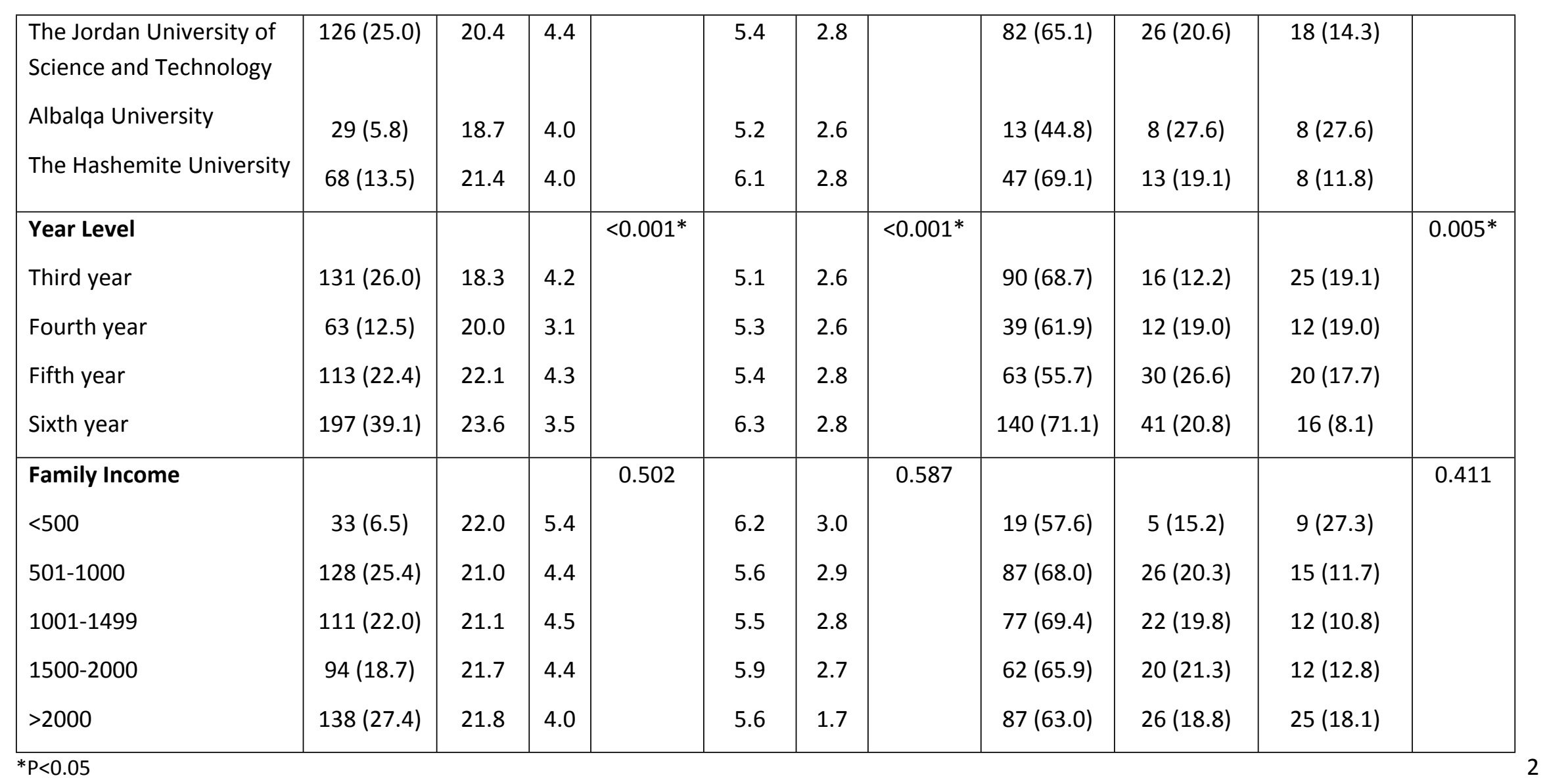




\section{Figure 1}

Figure1: Obstacle preventing form receiving or advice taking HPV vaccination

Figure1: Obstacle preventing form receiving or advice taking HPV vaccination

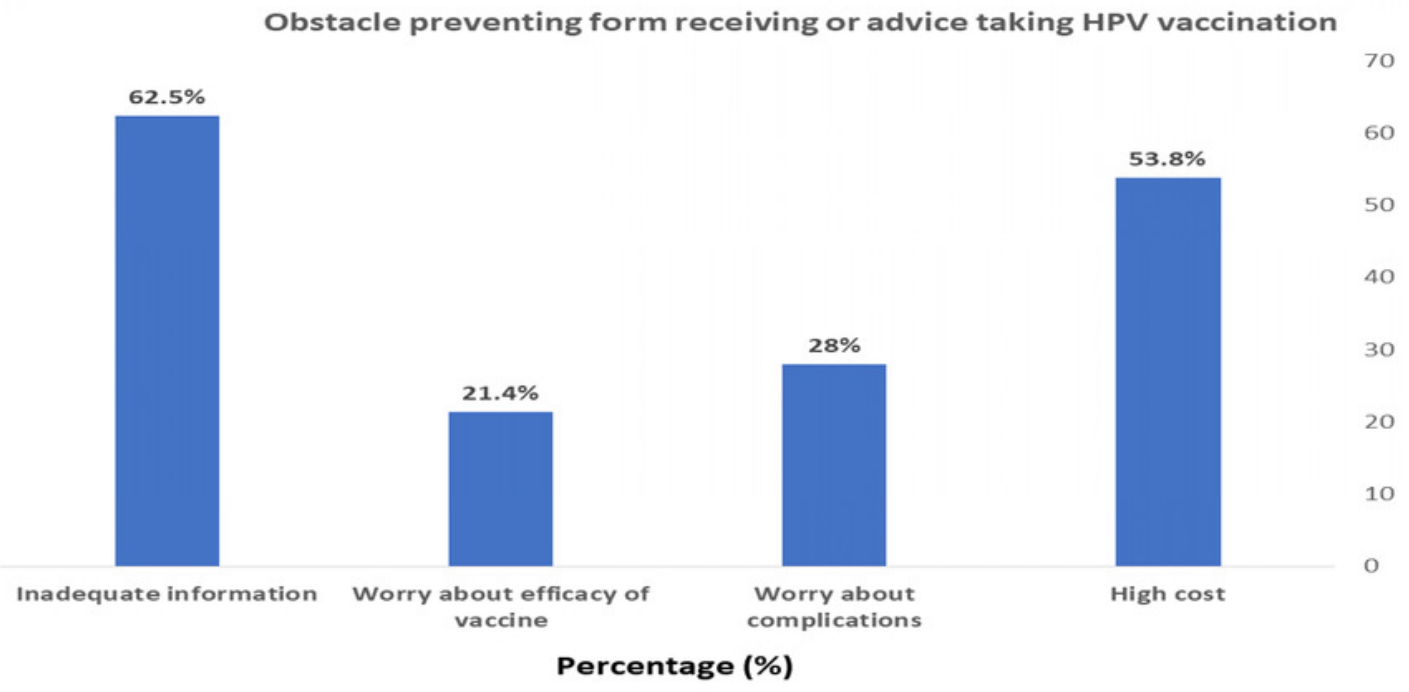




\section{Figure 2}

Figure1: Obstacle preventing form receiving or advice taking HPV vaccination

Figure2: Sources of knowledge and information on HPV vaccination

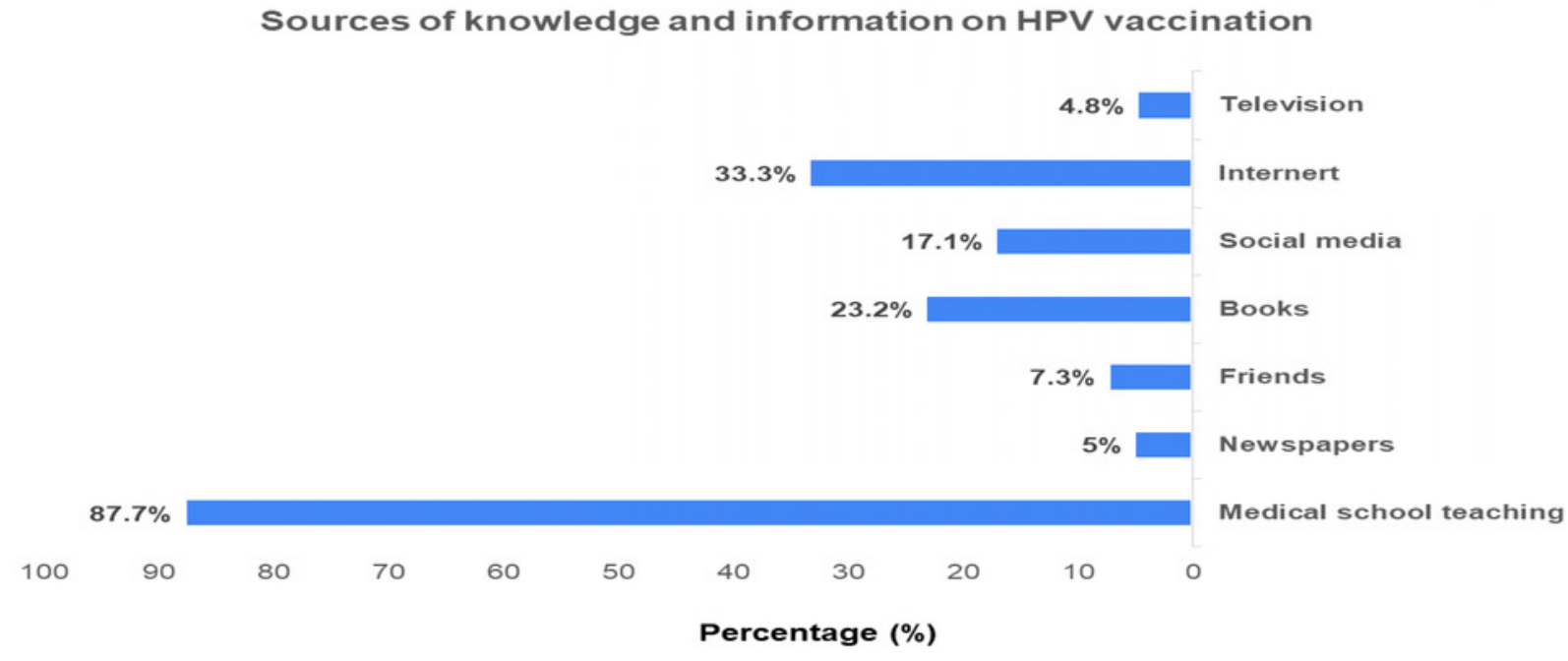

